\title{
Ações de enfermagem na educação em saúde do trabalhador em relação à imunização ocupacional
}

\author{
Actions of nursing school education on workers' health regarding occupational immunization
}

Ana Maria Silveira dos Santos Galarça ${ }^{1}$

\section{RESUMO}

A prevenção aos riscos aos quais o trabalhador da saúde está exposto está diretamente relacionada às questões de biossegurança e vacinação. Logo, a imunização se caracteriza como uma importante ferramenta de prevenção a agravos infectocontagiosos, inclusive aos profissionais de saúde, dentre eles, os profissionais de Odontologia. Trata-se de um estudo descritivo do tipo relato de experiência, resultante de uma atividade de educação em saúde vinculada ao projeto de extensão "Ações preventivas e corretivas em segurança do trabalho, de uma Faculdade de Odontologia do Rio Grande do Sul". A experiência trata da realização de atividades que envolveram palestras, roda de conversa, oficinas e campanhas de vacinação no período de março a novembro de 2019, no qual foram realizados seis encontros com média de 120 participantes por evento. Verificou-se que a atividade de educação em saúde aqui relatada foi significativa para todos os participantes envolvidos. Para os discentes e profissionais da unidade, foi capaz de ampliar o olhar a respeito dos temas discutidos; para os participantes do projeto, motivou-nos a prosseguir na caminhada proposta. Portanto, as ações de extensão preenchem a lacuna observada no âmbito da unidade a fim de contribuir de forma permanente e transformar as práticas profissionais.

Palavras-chave: Enfermagem. Vacinas. Educação em Saúde. Odontologia.

\begin{abstract}
The prevention of the risks to which the health worker is exposed is directly related to issues of biosafety and vaccination. Therefore, immunization is an important tool for the prevention of infectious and/or contagious diseases, including health professionals, subsuming dental professionals. This is a descriptive study of the experience report type, resulting from a health education activity linked to the extension project Preventive actions and corrective work safety of a School of Dentistry in Rio Grande do Sul. The experience deals with the realization of activities that involved lectures, conversation circles, workshops and vaccination campaigns from March to November 2019, in which six meetings were held with an average of 120 participants per event. It was found that the health education activity reported here was significant for all participants involved. For the students and professionals of the unit, it was able to broaden the view of the topics discussed. Therefore, extension actions fill the gap observed within the unit in order to permanently contribute and transform professional practices.
\end{abstract}

Keywords: Nursing. Vaccines. Health Education. Dentistry.

\footnotetext{
${ }^{1}$ Mestranda em Enfermagem na Universidade Federal de Pelotas, Rio Grande do Sul, Brasil; enfermeira na mesma instituição e na Secretaria de Saúde de Pelotas, Rio Grande do Sul, Brasil (anamariagalarca@gmail.com).
} 


\section{INTRODUÇÃO}

O profissional de enfermagem na função de educador em saúde vem desempenhando, ao longo do tempo, um protagonismo significativo em ações que possibilitam a transformação do processo saúde-doença por meio da ação educativa, bem como pelas novas formas de interpretação da realidade oferecidas pela aprendizagem (GALINDO NETO et al., 2013).

Por essa razão, a educação permanente em saúde tem sido utilizada como instrumento ativo, pois contribui para a organização da saúde do trabalhador e dispõe-se a transformar práticas profissionais na organização do trabalho, adotando como identificador as necessidades de saúde de cada pessoa, sendo, por isso, melhor executadas por uma equipe (YAMAMOTO; MACHADO; SILVA JÚNIOR, 2015; ABREU et al., 2019).

No Brasil, a prevenção aos riscos que o trabalhador da saúde está exposto é diretamente relacionada às questões de biossegurança e vacinação e, dentre eles, as hepatites virais são classificadas como as doenças que mais acometem esse grupo e como a principal fonte de transmissão ocupacional (CARVALHO; OLIVEIRA, 2015). Portanto, a imunização se caracteriza como uma importante ferramenta de prevenção a agravos infectocontagiosos, inclusive a profissionais de saúde, dentre eles, os profissionais de Odontologia.

Alguns dos principais riscos biológicos nas instituições de saúde advêm dos patógenos Influenza/H1N1, Sarampo, Caxumba, Rubéola, os vírus da Hepatite C (VHC) e da Hepatite B (VHB), dentre outros, os quais têm amplo impacto na saúde dos profissionais (GALARÇA et al., 2020; NÓVOA et al., 2020).

O Programa Nacional de Imunização (PNI) foi criado em 1973, pelo Ministério da Saúde, a fim de eliminar enfermidades que afetavam a população e a saúde pública brasileira. O PNI trabalha em conjunto com estados e municípios com a finalidade de alcançar metas de grupos (idosos, crianças, gestantes, profissionais, entre outros) a serem imunizados em todo o país, sendo reconhecido internacionalmente por atingir excelência (BRASIL, 2013; MORAIS et al., 2019).

O sistema de saúde brasileiro (BRASIL, 2003) busca promover a prevenção dos agravos que podem comprometer o bem-estar e a saúde da população. Logo, estar imunizado é uma das formas para se alcançar qualidade de vida (MORAIS et al., 2019). O Ministério da Saúde (MS) preconiza a imunização no calendário vacinal dos adultos com idade entre 19 e 49 anos, e em qualquer idade para os profissionais de saúde, com a comprovação sorológica após a terceira dose pelo exame Anti-Hbs, que verifica a imunidade adquirida contra o vírus da Hepatite B (BRASIL, 2013; OLIVEIRA et al., 2015). 
Além disso, considerando a importância da imunização destinada aos profissionais da área de saúde e seus objetivos, convém ressaltar sua implicação na proteção dos trabalhadores contra doenças a que eles estão expostos em consequência de sua área de atuação. Trata-se da cobertura dos riscos ligados à possibilidade de contato com fluidos orgânicos que podem veicular agentes biológicos patogênicos causadores de danos à saúde, e, ao mesmo tempo, transmitir agentes infecciosos (CANALLI; MORIYA; HAYASHIDA, 2011).

Profissionais e estudantes da área da saúde estão constantemente expostos a riscos biológicos e acidentes ocupacionais (SANTOS JÚNIOR et al., 2015). Em Odontologia, o risco biológico é aquele no qual o sangue em contato com mucosas pode ser uma via de transmissão de Hepatites virais e HIV, tanto quanto em exposições percutâneas (OLIVEIRA et al., 2018). Acidentes com perfurocortantes, os mais comuns na Odontologia, acontecem desde a formação profissional dos cirurgiões-dentistas. $\mathrm{O}$ início das atividades em âmbito clínico e o fator inexperiência têm sido vistos como fatores explicativos para o incremento de acidentes envolvendo material contaminante (MAZZUTTI et al., 2018).

Os cirurgiões dentistas, por desempenharem suas atividades profissionais em diferentes especialidades e contextos, podem se tornar grupo de risco de acidentes com material biológico. Isso ocorre por estarem diariamente expostos a microrganismos infecciosos a partir do manuseio de instrumentais contaminados e/ou atendimento ao paciente. Entre os acidentes possíveis, destacam-se aqueles que envolvem materiais perfurocortantes e fluidos corporais, devido ao manuseio de agulha, lâmina de bisturi, tesoura e outros equipamentos e instrumentais que possibilitam a transmissão de patógenos, como o vírus da Hepatite B (HBV), o vírus da Hepatite C (HCV) e o vírus da Imunodeficiência Humana (HIV) (PAIVA et al., 2017; SANGIORGIO et al., 2017).

Com enfoque na saúde dos profissionais e discentes da Faculdade de Odontologia (FO) da Universidade Federal de Pelotas (UFPel), o projeto realizou diversas atividades de educação permanente em saúde na unidade. Essas ações estão vinculadas a um projeto de extensão cadastrado no cobalto/ UFPel com o número 1581, que busca propor um trabalho de educação permanente sobre as imunizações necessárias aos profissionais de saúde, bem como atualizações sobre rotinas, normas, procedimentos de esterilização e desinfecção, precauções padrão e riscos ocupacionais, com a finalidade de acrescer a demanda de vacinação ocupacional entre os alunos e orientar quanto às normas de biossegurança.

Tendo em vista que se trata de um assunto de grande relevância, este trabalho tem como objetivo relatar a experiência da realização de atividades de educação permanente, com 
foco na prevenção de doenças infectocontagiosas, por meio de imunizações, junto a profissionais e discentes da FO/UFPEL.

\section{MATERIAL E MÉTODOS}

Trata-se de um estudo descritivo na modalidade de relato de experiência, a partir da vivência de uma equipe de Enfermagem como facilitadora em saúde de profissionais e discentes da Faculdade de Odontologia. A experiência trata da realização de atividades decorrentes do projeto de extensão "Ações preventivas e corretivas em segurança do trabalho" e que envolveram palestras, roda de conversa, oficinas e campanhas de vacinação no período de março a novembro de 2019, no qual foram realizados seis encontros com média de 120 participantes por evento. A coordenação do projeto procura manter boa relação com o Centro Acadêmico e representantes de turma, a fim de ampliar a divulgação por meio de grupos, redes sociais e cartazes no âmbito da faculdade para disseminar informações sobre os temas e as datas dos eventos.

O projeto de extensão é composto por uma equipe de cinco profissionais enfermeiros e dois técnicos de enfermagem vinculados e atuantes como promotores de educação permanente em saúde em uma instituição de ensino superior em Odontologia. Propostas de atuações, como campanha de vacinação semestral, das vacinas oferecidas ao trabalhador da saúde pelo MS, promoção de ciclo de palestras referentes à segurança do trabalhador foram algumas das atividades desenvolvidas por essa equipe de enfermagem.

\section{RESULTADOS E DISCUSSÃO}

A educação permanente em saúde tem impacto direto na vida do trabalhador, pois é uma das ferramentas mais importantes para a inclusão social e fundamental para a redução das desigualdades (ABREU et al., 2019). Como instrumento de ensino, a educação em saúde promove o aprimoramento do pensamento crítico e reflexivo, além de promover mudanças de hábitos. Ela ainda orienta os indivíduos para a autonomia de ações e a liberdade de opinar nas determinações em saúde para si, família e comunidade (FALKENBERG et al., 2014).

Com enfoque no fortalecimento do Sistema Único de Saúde (SUS), em 1970 foi instituída a Política Nacional de Educação Permanente em Saúde (PNEPS), a fim de proporcionar aprendizagem no ambiente de trabalho a partir dos problemas vivenciados na realidade dos serviços (CAMPOS; SENA; SILVA, 2017). 
O MS define educação em saúde como:

Processo educativo de construção de conhecimentos em saúde que visa à apropriação temática pela população [...]. Conjunto de práticas do setor que contribui para aumentar a autonomia das pessoas no seu cuidado e no debate com os profissionais e os gestores a fim de alcançar uma atenção de saúde de acordo com suas necessidades. (FALKENBERG et al., 2014).

Para Abreu et al. (2019), a educação permanente em saúde procura instigar a conscientização dos profissionais e levá-los à reflexão quanto a sua responsabilidade em seu processo permanente de capacitação, como também quanto à necessidade de priorizar a manutenção de sua saúde. Nesse contexto, vale ressaltar que o processo de educação permanente contribui para ampliar a qualificação dos profissionais e para a organização do serviço (CAMPOS; SENA; SILVA, 2017).

A imunização se caracteriza como uma importante ferramenta de prevenção a agravos infectocontagiosos, inclusive a profissionais de saúde, dentre eles, os da Odontologia.

Em seu estudo, Ferreira et al. (2018) revelam que poucos alunos estão cientes dos riscos que podem encontrar durante a graduação, visto que 15,5\% dos acadêmicos do primeiro ano não souberam responder se a atuação profissional traria algum risco para contrair doença ocupacional. Logo, para os estudantes, a imunização deve ser realizada nos primeiros semestres do curso, devido à necessidade de iniciar a vacinação antes do contato com os pacientes nas clínicas odontológicas (NUNES et al., 2016).

Para Campos, Sena e Silva (2017), a educação é prática transformadora e a aprendizagem é o enfoque fundamental da educação permanente, que se insere como recinto do saber e da prática na área da saúde. Assim, tem-se o entendimento que aumentar a adesão à vacinação entre os alunos durante a graduação é um desafio que se impõe às instituições de ensino, pois o fator educação permanente vem sendo apontado como um dos elementos-chave para o sucesso nessa questão (VIEIRA et al., 2013).

Considerando a importância da imunização, convém ressaltar sua implicação na proteção do trabalhador contra doenças a que eles estão expostos em consequência de sua área de atuação. Trata-se da cobertura dos riscos ligados à possibilidade de contato com fluidos orgânicos, que podem veicular agentes biológicos patogênicos causadores de danos à saúde, e, ao mesmo tempo, transmitir agentes infecciosos (CANALLI, MORIYA, HAYASHIDA, 2011; PAIVA et al., 2017). 
O maior índice de vacinação e de busca pela confirmação do status imunológico está entre os trabalhadores mais jovens, os quais experienciaram a oportunidade de atualizações e informações sobre a relevância dessa proteção em caso de acidente biológico (GUSMÃO et $a l .$, 2017). No entanto, existe uma controvérsia quando se associa cuidado ao profissional da saúde, pois esse trabalhador tem a sua formação voltada ao cuidado do outro e, muitas vezes, negligencia sua própria saúde. Alguns profissionais assumem uma posição de resistência diante dos riscos a que estão expostos e consequentemente pouco aderem às recomendações de prevenção, principalmente no que diz respeito à vacinação (DORNELLES et al., 2016; MACHADO et al., 2017).

Para tanto, Nunes et al. (2016) percebem que, aliados ao descrédito sobre a imunização, os profissionais ainda possuem fatores externos que fortalecem a falta de percepção sobre a importância de ser vacinado. A pouca informação sobre a gravidade dos riscos de contágio por sua constante exposição, o receio pelos efeitos colaterais e a sobrecarga profissional desestimulam esse trabalhador a buscar a imunização como medida preventiva.

Nesse sentido, buscou-se a partir do projeto de extensão supramencionado utilizar a educação permanente como ferramenta transformadora no cotidiano de discentes e profissionais da FO/UFPel. Essa proposta educativa, adicionada ao espaço de trabalho, coopera fortemente para a melhoria da qualidade dos serviços e das condições de trabalho, visto que busca aliar os conceitos da contextualização da realidade, da problematização, dos métodos de ensino inovadores e do pensamento reflexivo (MEDEIROS et al., 2020).

As ações ocorreram no auditório da FO/UFPel, sendo que, ao mesmo tempo em que acontecia o evento, mantiveram-se as atividades letivas diárias, e ainda foi possível a participação de técnicos, discentes e docentes. Buscou-se realizar o evento em pequenas rodas e palestras, mantendo-se a rotatividade, permitindo a participação de todos em pelo menos uma atividade.

A primeira ação educativa do projeto foi realizada em março de 2019. No encontro, compareceram como ouvintes, técnicos administrativos, alunos e docentes da instituição. A cartilha Vacinação do profissional de saúde: você tem este direito foi apresentada por meio de palestra com enfoque na conscientização sobre a imunização do trabalhador da saúde, bem como as vacinas preconizadas e ofertadas pelo Ministério da Saúde. Os discentes mostram-se receptivos à proposta, visto que relataram desconhecimento quanto às imunizações preconizadas pelo órgão, bem como a necessidade da imunização para a prática profissional.

Uma semana após esse evento, foi realizada uma campanha de vacinação interna, na FO/UFPel. Muitos alunos procuraram a equipe a fim de tirar dúvidas e pedir a conferência da 
carteira de vacinação. Como resultados das duas campanhas obteve-se a aplicação de 148 doses da Difteria e Tétano, 128 doses da Hepatite B, 145 doses da vacina Tríplice Viral e 100 doses da vacina Influenza.

Essas mesmas ações repetiram-se nos primeiros dias do segundo semestre letivo, em julho de 2019, ofertadas aos discentes dos semestres iniciais em Odontologia com um segundo momento da temática Vacinação do profissional de saúde: você tem esse direito. $\mathrm{O}$ evento ocorreu com participação ativa por parte dos discentes da unidade. Alguns dias após, uma nova ação de vacinação foi realizada na faculdade, a qual culminou em uma intensa procura, por parte de alunos e profissionais da unidade, a fim de atualizar a carteira de imunização.

Para Campos, Sena e Silva (2017), o controle efetivo da contaminação do local de trabalho é fundamental, bem como o conhecimento de alguns conceitos de biossegurança, controle de infecção e formas de transmissão de doenças ocupacionais. Sob esse aspecto, é necessário incorporar rotinas, normas, procedimentos de esterilização e desinfecção, precauções padrão e riscos ocupacionais, além dos cuidados com o meio ambiente pelo gerenciamento dos resíduos de saúde.

Devido à boa aceitação da proposta, o projeto "Ações preventivas e corretivas em segurança do trabalho" ampliou suas discussões em mais quatro encontros, com atividades realizadas ao longo do ano a respeito das temáticas: precauções padrão, riscos ocupacionais em saúde, limpeza, descartes e tipos de resíduos gerados em ambientes de saúde, além da conscientização sobre vacinação do profissional, totalizando seis encontros com média de 120 participantes por evento.

O projeto tem registrado presença e receptividade por parte dos alunos e profissionais da faculdade, o que culminou em convites para membros da equipe atuarem em outras atividades, como também em intercâmbios com outros projetos de extensão.

\section{CONSIDERAÇÕES FINAIS}

Verificou-se que as atividades de educação em saúde aqui relatadas foram significativas para todos os participantes envolvidos. Para os discentes e profissionais da unidade, foi capaz de ampliar o olhar a respeito dos temas discutidos; para os participantes do projeto, motivou-nos a prosseguir na caminhada proposta.

Portanto, as ações de extensão preenchem a lacuna observada no âmbito da unidade a fim de contribuir de forma permanente e transformar as práticas profissionais. 
A equipe de enfermagem, bem como técnicos administrativos da UFPel têm se preocupado em contribuir com a Faculdade de Odontologia no conhecimento de práticas relacionadas à saúde do trabalhador, bem como na segurança de seus alunos e profissionais. Nesse contexto, um conjunto de ações preventivas e corretivas em segurança do trabalho vem sendo realizadas ao longo do ano na instituição.

Observa-se mudança de comportamento em relação à procura por vacinas ocupacionais e também no aumento da participação dos alunos na medida em que os eventos são realizados.

Acredita-se que esse trabalho se estenda com novas iniciativas a partir das demandas que possam surgir na unidade, a fim de contribuir com ações educativas, não só no FO/UFPel, mas também em outras instituições que desejem percorrer o mesmo caminho.

\section{REFERÊNCIAS}

ABREU, V. C. et al. Educação permanente em saúde e sua implicância na saúde do trabalhador. Braz. J. Hea. Rev., São José dos Pinhais, v. 2, n. 4, p. 2.351-2.364, 2019. Disponível em: https://brazilianjournals.com/ojs/index.php/BJHR/article/view/1709. Acesso em: 25 jan. 2021.

BRASIL. Ministério da Saúde. Secretaria de Vigilância em Saúde. Coberturas Vacinais no Brasil: 2010-2014. Brasília-DF: Ministério da Saúde, 2015. Disponível em: https://siteal.iiep.unesco.org/sites/default/files/sit_accion_files/br_5113.pdf. Acesso em: 15 dez. 2020.

BRASIL. Ministério da Saúde. Secretaria de Vigilância em Saúde. Departamento de Vigilância das Doenças Transmissíveis. Programa Nacional de Imunizações (PNI): 30 anos. Brasília-DF: Ministério da Saúde, 2003. Disponível em:

https://bvsms.saude.gov.br/bvs/publicacoes/livro_30_anos_pni.pdf. Acesso em: 15 dez. 2020.

BRASIL. Ministério da Saúde. Secretaria de Vigilância em Saúde. Departamento de Vigilância das Doenças Transmissíveis. Programa Nacional de Imunizações (PNI): 40 anos. Brasília-DF: Ministério da Saúde, 2013. Disponível em:

https://bvsms.saude.gov.br/bvs/publicacoes/programa_nacional_imunizacoes_pni40.pdf. Acesso em: 15 dez. 2020.

CAMPOS, K. F. C.; SENA, R. R.; SILVA, K. L. Permanent professional education in healthcare services. Esc. Anna Nery, Rio de Janeiro, n. 21, v. 4, p. 1-10, 2017. Doi: 10.1590/2177-9465-EAN-2016-0317. Disponível em: https://www.scielo.br/j/ean/a/9vD6Ww7FyM9qHFKqgrRkT3c/?lang=en. Acesso em: 10 jan. 2021.

CANALLI, R. T. C.; MORIYA, T. N.; HAYASHIDA, M. Prevenção de acidentes com material biológico entre estudantes de enfermagem. Rev. Enferm. UERJ, Rio de Janeiro, n. 
1, v. 19, p. 1-6, 2011. Disponível em: https://pesquisa.bvsalud.org/portal/resource/pt/lil591023. Acesso em: 18 abr. 2021.

CARVALHO, M. J. A.; OLIVEIRA, A. H. A. Equipamentos de proteção individual em odontologia: revisão integrativa de literatura. Interfaces, Juazeiro do Norte, v. 3, n. 8, p. 1-6, 2015. Disponível em: https://interfaces.leaosampaio.edu.br/index.php/revistainterfaces/article/view/276. Acesso em: 18 abr. 2021.

DORNELLES, C. et al. Exposição de profissionais de saúde ao material biológico: estudo no ambiente hospitalar. JONAH, Pelotas, v. 6, n. 1, p. 64-75, 2016. Doi: 10.15210/JONAH.V6I1.5463. Disponível em: https://periodicos.ufpel.edu.br/ojs2/index.php/enfermagem/article/view/5463.Acesso em: 15 maio 2021.

FALKENBERG, M. B. et al. Educação em saúde e educação na saúde: conceitos e implicações para a saúde coletiva. Ciência \& Saúde Coletiva, Rio de Janeiro, v. 19, n. 3, p. 847-852, 2014. Doi: 10.1590/1413-81232014193.01572013. Disponível em: https://www.scielo.br/j/csc/a/kCNFQy5zkw4k6ZT9C3VntDm/?lang=pt. Acesso em: 15 mar. 2021.

FERREIRA, L. Q. et al. Hepatite B: conhecimento e atitudes de acadêmicos de Odontologia. Arch. health invest., Araçatuba, n. 7, v. 7, p. 258-261, 2018. Doi: 10.21270/archi.v7i7.3041. Disponível em: https://archhealthinvestigation.com.br/ArcHI/article/view/3041. Acesso em: 16 mar. 2021.

GALARÇA, T. Z. et al. Imunização ocupacional dos trabalhadores da saúde: revisão integrativa. Brazilian Journal of Health Review, São José dos Pinhais, v. 3, n. 4, p. 9.2059.223, 2020. Doi: 10.34119/bjhrv3n4-159. Disponível em:

https://www.brazilianjournals.com/index.php/BJHR/article/view/13808. Acesso em: 15 maio 2021.

GALINDO NETO, N. M. et al. Enfermagem do trabalho e intervenções na saúde do trabalhador. Rev. Enferm. UFPE, Recife, v. 7, n. 7, 2013. Doi: 10.5205/1981-8963v7i7a11744p4859-4867-2013. Disponível em:

https://periodicos.ufpe.br/revistas/revistaenfermagem/article/view/11744. Acesso em: 16 mar. 2021.

GUSMÃO, B. M. et al. Análise do perfil sociodemográfico de notificados para hepatite B e imunização contra a doença. Rev. Pesq. Cuid. Fund. Online, Rio de Janeiro, v. 9, n. 3, p. 627-633, 2017. Doi: 10.9789/2175-5361.2017.v9i3.627-633. Disponível em: http://www.seer.unirio.br/index.php/cuidadofundamental/article/view/5550. Acesso em: 15 maio 2021.

MACHADO, M. P. M. S. et al. Imunidade para Hepatite B entre trabalhadores de um hospital de referência em doenças infectocontagiosas, vítimas de acidente com material biológico. JHBS, Fortaleza, v. 5, n. 1, p. 62-70, 2017. Doi: 10.12662/23173076jhbs.v5i1.1018.p62-70.2017. Disponível em: https://periodicos.unichristus.edu.br/jhbs/article/view/1018. Acesso em: 15 maio 2021. 
MAZZUTTI, W. J. et al. Nível de informação de estudantes de odontologia sobre riscos, prevenção e manejo de acidentes com perfurocortantes. Rede de Cuidados em Saúde, Rio de Janeiro, v. 12, n. 2, p. 17-27, 2018. Disponível em:

http://publicacoes.unigranrio.edu.br/index.php/rcs/article/view/5401. Acesso em: 15 maio 2021.

MEDEIROS, L. S. et al. Cuidando de quem nos cuida: uma proposta de ação acerca da qualidade de vida do trabalhador. Braz. J. Hea. Rev., São José dos Pinhais, v. 4, n. 2, p. 6369-6379, 2021. Doi: 10.34119/bjhrv4n2-190. Disponível em: https://brazilianjournals.com/ojs/index.php/BJHR/article/view/26934. Acesso em: 10 fev. 2021.

MORAIS, D. F. L. et al. Análise da cobertura vacinal de 0 a 12 meses no município de Catende-PE. REBES, Paraíba, v. 9, n. 4, p. 165-170, 2019. DOI: 10.18378/rebes.v9i4.6640. Disponível em: http://www.gvaa.com.br/revista/index.php/REBES. Acesso em: 10 fev. 2021.

NÓVOA, T. D. et al. Cobertura vacinal do programa nacional de imunizações (PNI). Braz. J. Hea. Rev., São José dos Pinhais, v. 3, n. 4, p. 7863-7873, 2020. Doi: 10.34119/bjhrv3n4-053. Disponível em: https://brazilianjournals.com/ojs/index.php/BJHR/article/view/12969. Acesso em: 15 maio 2021.

NUNES, A. O. et al. Vacinação contra hepatite B em trabalhadores da saúde de um município da Bahia. Rev. Saúde Colet. UEFS, Feira de Santana, v. 5, n. 1, p. 9-16, 2016. Doi:

10.13102/rscdauefs.v5i1.1003. Disponível em: http://periodicos.uefs.br/index.php/saudecoletiva/article/view/1003. Acesso em: 15 mar. 2021.

PAIVA, S. N. et al. Acidentes ocupacionais com material biológico em Odontologia: uma responsabilidade no ensino. Revista da ABENO, Porto Alegre, v. 17, n. 3, p. 76-88, 2017. Doi: 10.30979/rev.abeno.v17i3.388. Disponível em:

https://revabeno.emnuvens.com.br/revabeno/article/view/388. Acesso em: 18 maio 2021.

SANGIORGIO, J. P. M. et al. Situação vacinal contra Hepatite B em estudantes de odontologia. REAS, São Paulo, v. 4, n. 9, p. 1225-1230, 2017. Doi: 10.25248/REAS37_2017. Disponível em: https://www.acervosaude.com.br/doc/REAS37.pdf. Acesso em: 18 maio 2021.

SANTOS JUNIOR, E. P. et al. Acidente de trabalho com material perfurocortante envolvendo profissionais e estudantes da área da saúde em hospital de referência. Revista Brasileira de Medicina do Trabalho, São Paulo, v. 13, n. 2, p. 69-75, 2015. Disponível em: https://pesquisa.bvsalud.org/portal/resource/pt/lil-775888. Acesso em: 10 maio 2021.

VIEIRA, R. H. G. et al. Vacinação contra influenza: construção de um instrumento educativo para maior adesão dos profissionais de enfermagem. Texto \& Contexto-Enfermagem, Florianópolis, v. 22, p. 603-609, 2013. Doi: 10.1590/S0104-07072013000300005. Disponível em: https://www.scielo.br/j/tce/a/SXqXFRmKzPjphfz8Wq9pJrr/?lang=pt. Acesso em: 18 abr. 2021.

YAMAMOTO, T. S.; MACHADO, M. T. C.; SILVA JÚNIOR, A. G. Educação permanente em saúde como prática avaliativa amistosa à integralidade em Teresópolis, Rio de Janeiro. Trabalho, Educação e Saúde, Rio de Janeiro, v. 13, n. 3, p. 617-638, 2015. Doi: 
10.1590/1981-7746-sip00058. Disponível em:

https://www.scielo.br/j/tes/a/FLHsqBHmZZqm4CRsMnJkZkf/?lang=pt. Acesso em: 20 dez. 2020.

Submetido em 23 de fevereiro de 2021.

Aprovado em 18 de agosto de 2021. 